\title{
Preferences in relation to Video Lecture Styles: A Survey with Students and Teachers of Distance Education Technical Courses of the Open Technical School of Brazil
}

\author{
Solange Fávero de Lima Medeiros, UTFPR, sflmedeiros@outlook.com \\ Luciano Tadeu Esteves Pansanato, UTFPR, luciano@utfpr.edu.br
}

\begin{abstract}
The use of video lectures has increased considerably in the past years. The interest of students and teachers has grown in part because of several initiatives that provide access to video lectures through the Internet. This paper presents a survey with students and teachers of distance education technical courses of the Open Technical School of Brazil. The questionnaires were different for students and teachers and contained questions about preferences regarding video lecture styles and average duration of video lectures, questions to identify the agreement level regarding some statements about video lectures and, only for teachers, questions regarding video lecture production. The results suggest some directions for planning a training program for teachers on production of video lectures.
\end{abstract}

Keywords: distance education; video lecture styles; video lecture production; students' preferences; teachers' preferences.

\section{Preferências em relação a Estilos de Videoaula: Um Survey com Alunos e Professores de Cursos Técnicos a Distância da Escola Técnica Aberta do Brasil}

Resumo. O uso de videoaulas aumentou consideravelmente nos últimos anos. O interesse de alunos e professores tem crescido em parte devido a várias iniciativas que fornecem acesso a videoaulas por meio da Internet. Neste artigo é apresentado um survey com alunos e professores de cursos técnicos a distância da Escola Técnica Aberta do Brasil. Os questionários foram diferentes para alunos e professores e contêm questões sobre as preferências em relação a estilos de videoaula e duração média de videoaulas, questões para identificar o nível de concordância em relação a declarações sobre videoaulas e, somente para professores, questões sobre produção de videoaulas. Os resultados apontam algumas direções para o planejamento de um programa de treinamento para professores na produção de videoaulas.

Palavras-chave: educação a distância; estilos de videoaula; produção de videoaula; preferências de alunos; preferências de professores.

\section{Introduction}

The use of video lectures has increased considerably in the past years. The interest of students and teachers has grown in part because of several initiatives that provide access to video lectures through the Internet, such as Khan Academy and edX. Many teachers produce video lectures in various formats and with diverse purposes, e.g., for distance education and to support or complement in-person classes. Due to increasing use of video lectures, it is important to conduct research to know preferences of students and teachers, as well as aspects related to production of video lectures by teachers. The focus of studies found in the literature related to video lecture styles (Guo et al., 2014; Cross et al., 2013; Dotta et al., 2013; Ilioudi et al., 2013; Vieira et al., 2014; Brecht, 2012; Gilard 
et al., 2015) has been mainly to determine which aspects of video lecture can interfere in the teaching-learning process or to identify which of these aspects lead to better learning outcomes. Nevertheless, these studies little explored preferences of students and teachers regarding video lectures and aspects related to production of video lectures by teachers.

The Open Technical School of Brazil (e-Tec Brasil) of the Ministry of Education (MEC) provides subsequent technical courses to high school in suburbs of Brazilian large cities and in areas that are distant from large cities. The e-Tec Brasil aims at developing and expanding the public and free professional education through distance learning. From 2007 to 2013, the Federal University of Technology - Paraná (UTFPR) offered 18 technical courses. In the courses offered by UTFPR, classes are transmitted to support centers and made available in the format of video lectures through a virtual learning environment (VLE). Therefore, students and teachers of these courses have relevant experience with video lectures. The possibility of carrying out the study with a sample of students and teachers of these technical courses was the initial motivation for this study.

The main objective of the study presented in this paper was to identify preferences in relation to video lecture styles aiming at improving the quality of distance education in the UTFPR. The proposed study involved conducting a survey as research methodology. The results provided important information regarding preferences of students and teachers as also information on production of video lectures by teachers. This information will be the basis for developing a training program for teachers as initial action to improve the quality of distance education in the UTFPR.

\section{Related Work}

Researchers have recognized that different video lecture styles may have different learning effects and there is a diversity of styles described in the literature. Guo et al. (2014) describes four video lecture styles: traditional style (traditional lecture presented in class); talking head style (top of teacher's body talks to camera); voice and presentation style (teacher's voice with a slideshow); Khan-style tutorial (voice with manual writing and drawing on a tablet). The name Khan is because the style was popularized by Khan Academy (founded by Salman Khan). The style considered more engaging for learning was the Khan-style tutorial. Some of these video lecture styles are also described by other authors.

Cross et al. (2013) evaluated the students' preference regarding two video lecture styles: manual writing and drawing on an electronic whiteboard (Khan style) and digital writing, typewritten, in a presentation with PowerPoint. A new video lecture style called TypeRighting was used where words are handwritten, but soon after they appear, they convert into typeface. Interviews showed a significant preference for TypeRighting style. The TypeRighting style can be considered as a specific modification of Khan-style tutorial used by Guo et al. (2014).

The objective of Dotta et al. (2013) was to analyze the students' preference in the use of video lectures using the image, voice and presentation style. The video lectures were produced capturing the image and audio of teacher during slideshow, with later capture only of the slideshow according to the audio recorded in the previous stage and editing of the items produced in the previous stages for synchronization and addition of animation elements. The style called image, voice and presentation is present in Guo et al. (2014), but without animation elements.

Ilioudi et al. (2013) created two videos for teaching three predefined modules of mathematics, one in talking head style with the aid of a blackboard and the other in Khan style (voice with manual writing and drawing on an electronic whiteboard). The approach 
that caused the greatest impact on learning was the talking head style (with a blackboard). The Khan style used by Ilioudi et al. (2013) is slightly different from Khan-style tutorial of Guo et al. (2014).

Vieira et al. (2014) developed mathematics video lectures for online courses using voice and presentation style after also analyzing other styles present in video lectures, such as traditional, talking head and interactive style. The interactive style is a video lecture with several interactive elements such as exercises and animations. The style called voice and presentation was also approached by Guo et al. (2014), Cross et al. (2013), Brecht (2012) and Gilard et al. (2015). Vieira et al. (2014) concluded that it is important to promote the interaction of the student with video lectures, produce short video lectures, avoid abrupt transitions and provide interactive links.

Brecht (2012) tested three video lecture designs: with absence of attention to relief and change-of-pace elements (traditional style); with graphics and sounds/musical clips that were presented to provide relief from study tedium (voice and presentation style with interactive elements); with a greatly reduced number of graphics and sounds that were subtly presented so that they did not draw viewer attention (voice and presentation style). The students had better performance with the voice and presentation style with interactive elements. The use of interactive elements in video lectures for promoting student interaction and facilitating learning was highlighted by Vieira et al. (2014) and Dotta et al. (2013).

Gilard et al. (2015) presented five video lecture styles to participants of their study: voice and presentation; image, voice and presentation; traditional; SussexDL; and personal. In SussexDL, the teacher is physically superimposed on the slide during recording and purposeful animations are a key part of this style. In personal style the lecture is given live to the student in an individual tutoring session. The SussexDL, which was considered more engaging, is like the image, voice and presentation style present in Dotta et al. (2013). Furthermore, Dotta et al. (2013), Vieira et al. (2014) and Brecht (2012) have also emphasized the importance of using animations in video lectures.

In summary, some studies on video lecture styles aim at verifying whether the style can interfere in student's engaging within teaching-learning process (Guo et al. 2014; Vieira et al. 2014; Gilard et al. 2015). Other studies aim identify which style lead to better learning outcomes (Ilioudi et al. 2013; Brecht 2012). Cross et al. (2013) and Dotta et al. (2013) have explored the students' preferences concerning video lecture styles. However, the selection of a style for a video lecture can also depend on the teacher's preference. Moreover, the aspects related to production of video lectures by teachers are poorly explored in the reviewed studies. This paper presents the preferences of students and teachers in relation to video lecture styles commonly used in distance education technical courses.

\section{Methodology}

The methodology used in this study on video lectures was the survey. A survey uses instruments that allows measuring or describing a problem, a phenomenon or an object of study. The questionnaire was the technique used to collect data. The survey was conducted in five stages: (1) elaboration of data collection instruments (questionnaires); (2) pretest of questionnaires; (3) selection of sample; (4) application of questionnaires; and (5) analysis and interpretation of data. 


\subsection{Data Collection Instrument}

The video lecture styles considered in data collection instruments (questionnaires) were the following: traditional; talking head; voice and presentation; image, voice and presentation; Khan (voice with manual writing and drawing on an electronic whiteboard); and tutorial (voice and step by step demonstration of a task in a software). These styles are often found in video lecture repositories at UTFPR. Specifically, the questionnaire for teachers also included questions on knowledge of methods and tools (and its preferences) for producing video lectures.

The questionnaire for students has three sections:

- Section 1 - Demographic and experience information. In this section, questions aim to identify personal and academic information of the student, e.g., gender, age, course in which he/she is enrolled, period which he/she is attending classes, and information on experience with computers (desktop, files and folders, applications for text editing and presentation creating) and experience with the Web (browsers, search engines, social networks etc.).

- Section 2 - Use and preference. In this section, questions aim to identify information on use of video lectures and preferences regarding video lecture styles and average duration of video lectures.

- Section 3 - Statements about video lectures. In this section, questions aim to identify the agreement level (in seven-point Likert scale) regarding some statements: if video lecture style can interfere in the learning process; if video lecture in which the teacher speaks fast and with great enthusiasm is more engaging; if video lecture in which the teacher talks rhythmically facilitates understanding; and if video lecture that interpolates teacher's image with slides is more attractive.

The questionnaire for teachers has four sections:

- Section 1 - Demographic and experience information. In this section, questions aim to identify personal and professional information of the teacher, e.g., gender, age, education, length of professional experience, and information on experience with computers and experience with the Web.

- Section 2 - Use and preference. In this section, questions aim to identify information on use of video lectures and preferences regarding video lecture styles and average duration of video lectures.

- Section 3 - Statements about video lectures. In this section, questions are the same present in questionnaire for students.

- Section 4 - Aspects related to video lecture production. In this section, only present in questionnaire for teachers, questions aim to identify information regarding the frequency of video lecture production, methods and tools used in video lecture production.

At the beginning of questionnaires, the respondents were informed that participation is not mandatory, they are free to refuse to participate, and they could request more information via researchers' e-mails. Furthermore, the respondents were informed that their names would be kept confidential, results would be used anonymously, and all connections between respondents and their data would be destroyed after the study. The average time to answer the questionnaire, eight minutes for students and ten minutes for teachers, was also informed to respondents.

An "Informed Consent Form" was inserted at the beginning of questionnaires. The research project was submitted to Research Ethics Committee of the UTFPR and was 
approved on July 24, 2015, approval letter number 1.158.917, under Certificate of Presentation for Ethical Consideration number 442778915.5.000.5547.

\subsection{Procedure and Sample}

In pretest, the questionnaire for students was applied to 18 respondents and the questionnaire for teachers was applied to 10 respondents. Ten to twenty respondents are sufficient to validate a data collection instrument regardless of sample size (Grossman et al. 2009). The pretest is a pilot study conducted prior to the application of questionnaire to improve its final version. The pretest's respondent could also provide, in an open question, an opinion about the quality of the questions and suggest some improvement. There was a comment in the questionnaire for students on a question with multiple answers that required the selection of at least three alternatives; after analysis, this restriction was removed. No respondent reported any other difficulty in answering the questions.

The questionnaire was sent to 446 students and 49 teachers of three distance education technical courses: Computer Networks, Electronics, and Computer Maintenance and Support. The population of students and teachers of these technical courses is adequate for the survey due to its experience with video lectures and the practicality of access to potential respondents.

The sample was determined by using convenience sampling, a non-probability sampling. The message to respondents included a link to the online questionnaire webpage that was available for 51 days and received 97 responses from students and 39 responses from teachers (which corresponds to a response rate of $21.7 \%$ and $79.5 \%$ respectively). The data were formatted in a spreadsheet and imported into a statistical tool to facilitate analysis. Data analysis was carried out mainly through descriptive analysis.

For the questions in Section 3, that aim to identify the agreement level regarding some statements about video lectures, an inferential statistical analysis was performed to compare responses of students and teachers. The hypotheses were defined according to results obtained in the descriptive analysis considering the median of data (responses to questions in Likert scale). To draw conclusions, the Mann-Whitney statistical test was used to compare the equality between the medians of responses (students and teachers) with $\alpha=0.05$ and a 95\% confidence interval. The Mann-Whitney test was chosen for hypothesis testing because it is a nonparametric test for independent samples and of different sizes. A nonparametric statistical test was necessary because the data do not follow a normal distribution; the hypothesis of normality were rejected by using the Anderson-Darling normality test. Moreover, the Mann-Whitney test is suitable for comparing if the median of a sample has an equivalent value to the second sample and it is often used for analysis of ordinal or categorical data, for example, data in Likert scale (Winter and Dodou, 2010).

\subsection{Threats to Validity}

A research instrument has its validity related to the confidence level of all elements involved in the research process. This subsection discusses threats to validity of the comparison between students and teachers performed by inferential statistical analysis.

The responses of questionnaires should be reliable to draw the right conclusion on the relationship between data. The Cronbach's Alpha Coefficient (Cronbach, 1951) was 
used to analyze the reliability of the responses. This coefficient ranges from zero to one, and the higher the value, the greater the reliability. A value of at least 0.7 reflects an acceptable reliability (Cronbach and Shavelson, 2004; Streiner, 2003). For the questions in Likert scale, the values obtained for the Cronbach's Alpha Coefficient were 0.955 for responses of the questionnaire for students and 0.956 for responses of the questionnaire for teachers. These values indicate that the variation of responses presents an acceptable reliability.

The application of questionnaires for students and teachers with experience in video lectures minimizes the difficulty in generalizing results obtained by inferential statistical analysis. According to the results presented in Subsection 4.1, students and teachers of the sample has experience with video lectures to respond to questionnaires properly. Nonetheless, the sample can be considered specialized, since all respondents attend distance education technical courses of the Open Technical School of Brazil (eTec Brasil) offered by UTFPR. In this case, this condition limits the ability to generalize the results towards other populations.

\section{Results of Statistical Analysis}

This section presents the results of statistical analysis of the data obtained from the questionnaires. Initially, a subsection presents demographic and experience information of the respondents. Then, the results obtained by descriptive statistical analysis regarding styles and duration of video lectures are presented. Subsequently, a subsection presents the results concerning video lecture production by teachers. After that, a subsection presents the results of a comparison between students and teachers performed by inferential statistical analysis regarding the agreement level concerning statements on video lectures.

\subsection{Demographic and Experience Information of the Sample}

Considering the total of respondents (students), $88.7 \%$ are male and $48.5 \%$ are between 21 and 30 years old (15.5\% are between 18 and 20, 20.6\% are between 31 and 40 and $15.5 \%$ are over 40 ). $69.1 \%$ of students are enrolled only in a technical course and $26.9 \%$ are technical and undergraduate students (in some cases they are taking technical and undergraduate courses simultaneously and others are finishing the technical course). Among students, $85.6 \%$ classify as excellent or good their experience with computers (desktop, files and folders, applications for text editing and presentation creating) and 90.7\% classify as excellent or good their experience with the Web (browsers, search engines, social networks etc.).

The respondents (students) confirmed (Section 2 of the questionnaire) that they used video lectures for learning: video lectures searched on the Internet $(69.1 \%)$, provided by teacher $(63.9 \%)$ or indicated by colleagues $(30.9 \%)$. Furthermore, respondents also experimented different styles, especially tutorial (66\%), voice and presentation $(55.7 \%)$, image, voice and presentation (51.5\%), Khan (43.3\%), traditional (43.3\%) and talking head $(38.1 \%)$.

Regarding teachers, all have taught or are teaching subjects in technical courses of e-Tec Brasil. Considering the total of respondents (teachers), $74 \%$ are male and $38.5 \%$ are between 31 and 40 years old (7.7\% are between 20 and 30,30.8\% are between 41 and 50 and $23 \%$ are over 50 ). Among teachers, $41 \%$ has doctorate, $46.2 \%$ has master, and $12.8 \%$ are specialists; $53.8 \%$ have been teaching for over 16 years $(10.3 \%$ have been teaching from 1 to 5 years and $17.9 \%$ from 6 to 15 years); the expertise area is diverse: 
computer science, languages, electrical/electronic engineering, and management. 94.9\% of the teachers classify as excellent or good their experience with computers (desktop, files and folders, applications for editing and creating presentations) and $89.79 \%$ classify as excellent or good their experience with the Web (browsers, search engines, social networks etc.).

The respondents (teachers) confirmed (Section 2 of the questionnaire) that they used video lectures for teaching: video lectures produced by themselves $(84.6 \%)$, provided by colleagues $(35.9 \%)$ or searched on the Internet $(30.8 \%)$. Moreover, respondents also used different styles, especially voice and presentation (69.2\%), tutorial (53.8\%), image, voice and presentation (48.7\%), talking head (41\%), Khan (33.3\%) and traditional $(30.8 \%)$.

The number of respondents who participated in this survey is a significant sample for identifying preferences regarding video lectures. All respondents confirmed that they used video lectures for learning (students) or for teaching (teachers). In addition, both students and teachers had contact with different video lecture styles (all respondents confirmed to know more than one style).

\subsection{Preferences regarding Styles and Duration of Video Lectures}

Students selected video lecture styles that they prefer to use for learning by means of a multiple-choice question (multiple answers). The Table 1 shows the frequency of responses. The students' preference for tutorial style $(58.8 \%)$ may be related to the technical nature of the subject matters, that repeatedly need presentations of "how-to" and the tutorial style meets this demand. Guo et al. (2014) also identified the students' preference for tutorials (Khan-style tutorial).

Table 1 - Frequency of students' responses regarding video lecture styles

\begin{tabular}{|l|c|c|}
\hline \multicolumn{1}{|c|}{ Video lecture styles } & \multicolumn{2}{c|}{ Frequency } \\
\hline Tutorial & 57 & $58.8 \%$ \\
\hline Image, voice and presentation & 52 & $53.6 \%$ \\
\hline Khan & 40 & $41.2 \%$ \\
\hline Traditional & 36 & $37.1 \%$ \\
\hline Voice and presentation & 30 & $30.9 \%$ \\
\hline Talking head & 23 & $23.7 \%$ \\
\hline I have no preference & 08 & $8.2 \%$ \\
\hline
\end{tabular}

Teachers selected video lecture styles that they prefer to produce for teaching. Teachers prefer to produce voice and presentation $(48.7 \%)$ and image, voice and presentation (43.6\%), as shown in Table 2. On the one hand, there is a conflict with the main students' preference for tutorial style (58.8\%); on the other hand, $30.9 \%$ of the students also prefer voice and presentation style and 53.6\% prefer image, voice and presentation style. Furthermore, the tutorial style is the third style that most teachers prefer to produce $(33.3 \%)$, after the preference for image, voice and presentation style (43.6\%). When asked in an open question, the respondents (students and teachers) said that they do not know any other video lecture style.

Table 3 presents the frequency of responses (students and teachers) regarding duration of video lectures. The students prefer short video lectures because most selected options were 11 to 20 minutes (35.1\%) and 21 to 40 minutes (30.9\%). Just as the students, teachers also prefer short video lectures. Most teachers' responses to the question on duration of video lecture were also 11 to 20 minutes $(38.5 \%)$ and 21 to 40 minutes 
(30.8\%). Dotta et al. (2013), Guo et al. (2014) and Vieira et al. (2014) emphasized the need to provide short video lectures to students.

Table 2 - Frequency of teachers' responses regarding video lecture styles

\begin{tabular}{|l|c|c|}
\hline \multicolumn{1}{|c|}{ Video lectures styles } & \multicolumn{2}{c|}{ Frequency } \\
\hline Voice and presentation & 19 & $48.7 \%$ \\
\hline Image, voice and presentation & 17 & $43.6 \%$ \\
\hline Tutorial & 13 & $33.3 \%$ \\
\hline Khan & 09 & $23.1 \%$ \\
\hline Traditional & 08 & $20.5 \%$ \\
\hline Talking head & 07 & $17.9 \%$ \\
\hline I have no preference & 04 & $10.3 \%$ \\
\hline
\end{tabular}

Table 3 - Frequency of responses regarding duration of video lectures

\begin{tabular}{|l|c|c|c|c|}
\hline \multicolumn{1}{|c|}{ Video lecture duration } & \multicolumn{2}{c|}{ Frequency (students) } & \multicolumn{2}{c|}{ Frequency (teachers) } \\
\hline Up to $10 \mathrm{~min}$ & 10 & $10.3 \%$ & 06 & $15.4 \%$ \\
\hline 11 to $20 \mathrm{~min}$ & 34 & $35.1 \%$ & 15 & $38.5 \%$ \\
\hline 21 to $40 \mathrm{~min}$ & 30 & $30.9 \%$ & 12 & $30.8 \%$ \\
\hline 41 to $60 \mathrm{~min}$ & 16 & $16.5 \%$ & 05 & $12.8 \%$ \\
\hline Over $61 \mathrm{~min}$ & 06 & $6.2 \%$ & 01 & $2.6 \%$ \\
\hline Other & 01 & $1.0 \%$ & - & - \\
\hline
\end{tabular}

\subsection{Teachers' Preferences regarding Video Lecture Production}

Teachers commented on the main reasons for producing video lectures in an open question. The following reasons summarize the main reasons presented:

- Presentation of a subject matter that exceeds the lesson time;

- The need of specific courses in distance learning;

- Unavailability of video lectures related to a specific technical content.

Table 4 shows the results regarding frequency that teachers produce video lectures. Despite reasons presented above, the frequency of video lecture production is low because only $25.6 \%$ responded always or often. This low frequency can be explained by the habit of producing a video lecture once and then reusing this same video lecture in other opportunities. Moreover, there are cases of teachers who use video lectures produced by other teachers.

Table 4 - Frequency of teachers' responses regarding frequency of video lecture production

\begin{tabular}{|l|c|c|}
\hline \multicolumn{1}{|c|}{ Frequency of video lecture production } & \multicolumn{2}{c|}{ Frequency } \\
\hline Never & - & - \\
\hline Rarely & 09 & $23.2 \%$ \\
\hline Sometimes & 20 & $51.2 \%$ \\
\hline Often & 08 & $20.5 \%$ \\
\hline Always & 02 & $5.1 \%$ \\
\hline
\end{tabular}

Guo et al. (2014) and Vargas et al. (2007) refer to video lecture production stages, called planning (pre-production), recording (production), and editing (post-production), as being a well-defined process to produce video lectures. However, in response to a question, most teachers (53.9\%) said that they do not know these video lecture production stages, as shown in Table 5. Although only $12.8 \%$ of the teachers responded that know and they have used these stages, in another question, $87.2 \%$ said that are predisposed to learn new methods and techniques to produce video lectures.

Table 6 shows the frequency of teachers' responses regarding tools used to produce video lectures (multiple-choice question). The main tools used are Camtasia Studio (61.5\%) and Windows Movie Maker (43.6\%). Considering the total of teachers, 
$17.9 \%$ indicated that they do not use specific tools, therefore, they depend on other people to produce their video lectures or they use already available video lectures (produced by colleagues or searched on the Internet). Additionally, $87.2 \%$ of teachers responded in another question that they are predisposed to learn new tools for producing video lectures.

Table 5 - Frequency of teachers' responses regarding video lecture production stages

\begin{tabular}{|l|c|c|}
\hline \multicolumn{1}{|c|}{ Knowledge of the video lecture production stages } & \multicolumn{2}{c|}{ Frequency } \\
\hline No, but I am interested in knowing them & 12 & $30.8 \%$ \\
\hline No & 09 & $23.1 \%$ \\
\hline Yes, but I have not used them & 13 & $33.3 \%$ \\
\hline Yes, and I have already used them & 05 & $12.8 \%$ \\
\hline
\end{tabular}

Table 6 - Frequency of teachers' responses regarding production tools

\begin{tabular}{|l|c|c|}
\hline \multicolumn{1}{|c|}{ Tools } & \multicolumn{2}{c|}{ Frequency } \\
\hline Camtasia Studio & 24 & $61.5 \%$ \\
\hline Windows Movie Maker & 17 & $43.6 \%$ \\
\hline None / I do not use them & 07 & $17.9 \%$ \\
\hline Other & 06 & $15.4 \%$ \\
\hline Wink & 02 & $5.1 \%$ \\
\hline Adobe Captivate & 01 & $2.6 \%$ \\
\hline Echo360 & 01 & $2.6 \%$ \\
\hline
\end{tabular}

\subsection{Agreement of Students and Teachers regarding Statements about Video Lectures}

The respondents (students and teachers) expressed their agreement level regarding four statements about video lectures by means of questions in seven-point Likert scale (from 1, strongly disagree, to 7, strongly agree). Table 7 shows the result for students. The most respondents chose 6 or 7 to statements 1, 3 and 4 (respectively, 69.0\%, 58.8\% and $57.7 \%$ of students, with median 6 and mode 7 for the three statements). Table 8 shows the result for teachers regarding the same statements presented to students. Similarly, most teachers also chose 6 or 7 to statements 1, 3 and 4 (respectively, 64.1\%, 61.6\% and $56.4 \%$ of teachers, with median 6 and mode 7 ).

Table 7 - Frequency of students' responses to the questions in Likert scale about video lectures

\begin{tabular}{|l|c|c|c|c|c|c|c|c|c|}
\hline \multirow{2}{*}{ Statement } & \multicolumn{7}{|c|}{ Frequency (\%) } & \multirow{2}{*}{ Med } & Mod \\
\cline { 2 - 11 } & $\mathbf{1}$ & $\mathbf{2}$ & $\mathbf{3}$ & $\mathbf{4}$ & $\mathbf{5}$ & $\mathbf{6}$ & $\mathbf{7}$ & & \\
\hline $\begin{array}{l}\text { 1. The video lecture style can } \\
\text { interfere in the learning process }\end{array}$ & 1.0 & - & 1.0 & 13.4 & 15.5 & 21.6 & 47.4 & 6 & 7 \\
\hline $\begin{array}{l}\text { 2. The video lecture in which the } \\
\text { teacher speaks fast and with great } \\
\text { enthusiasm is more engaging }\end{array}$ & 6.2 & 6.2 & 11.3 & 19.6 & 20.6 & 12.4 & 23.7 & 5 & 7 \\
\hline $\begin{array}{l}\text { 3. The video lecture in which the } \\
\text { teacher talks rhythmically } \\
\text { facilitates understanding }\end{array}$ & 2.1 & 3.1 & 6.2 & 14.4 & 15.5 & 15.5 & 43.3 & 6 & 7 \\
\hline $\begin{array}{l}\text { 4. The video lecture that } \\
\text { interpolates teacher's image with } \\
\text { slides is more attractive }\end{array}$ & 2.1 & 8.2 & 6.2 & 9.3 & 16.5 & 24.7 & 33.0 & 6 & 7 \\
\hline
\end{tabular}


Table 8 - Frequency of teachers' responses to the questions in Likert scale about video lectures

\begin{tabular}{|l|c|c|c|c|c|c|c|c|c|}
\hline \multirow{2}{*}{ Statement } & \multicolumn{7}{|c|}{ Frequency (\%) } & \multirow{2}{*}{ Med } & Mod \\
\cline { 2 - 10 } & $\mathbf{1}$ & $\mathbf{2}$ & $\mathbf{3}$ & $\mathbf{4}$ & $\mathbf{5}$ & $\mathbf{6}$ & $\mathbf{7}$ & & \\
\hline $\begin{array}{l}\text { 1. The video lecture style can } \\
\text { interfere in the learning process }\end{array}$ & - & - & 2.6 & 20.5 & 12.8 & 15.4 & 48.7 & 6 & 7 \\
\hline $\begin{array}{l}\text { 2. The video lecture in which the } \\
\text { teacher speaks fast and with great } \\
\text { enthusiasm is more engaging }\end{array}$ & 2.6 & 5.1 & 12.8 & 17.9 & 30.8 & 10.3 & 20.5 & 5 & 5 \\
\hline $\begin{array}{l}\text { 3. The video lecture in which the } \\
\text { teacher talks rhythmically } \\
\text { facilitates understanding }\end{array}$ & - & 2.6 & 7.7 & 12.8 & 15.4 & 23.1 & 38.5 & 6 & 7 \\
\hline $\begin{array}{l}\text { 4. The video lecture that } \\
\text { interpolates teacher's image with } \\
\text { slides is more attractive }\end{array}$ & - & 2.6 & - & 17.9 & 23.1 & 23.1 & 33.3 & 6 & 7 \\
\hline
\end{tabular}

The result for students and teachers regarding statements about video lectures was compared by using inferential statistical analysis. The hypotheses concerning the statements assessed by respondents were elaborated based on Table 7 and Table 8 to verify if the difference between medians is statistically significant. The null hypothesis $\left(\mathrm{H}_{0}\right)$ states that the medians of the two populations are equivalent and the alternative hypothesis $\left(\mathrm{H}_{1}\right)$ states that the medians of the two populations are not equivalent. The hypotheses were tested by means of Mann-Whitney test using the statistical software Minitab (http://www.minitab.com/). In Minitab, the Mann-Whitney test considers as null hypothesis that two independent groups have equivalent medians. The Mann-Whitney test was performed considering a significance level $\alpha=0.05$ and a $95 \%$ confidence interval.

Table 9 shows the results (p-value) of the Mann-Whitney test. The conclusion for statements 1, 2, 3 and 4 is that the $\mathrm{H}_{0}$ hypothesis of equivalence between medians of the two populations (students and teachers) cannot be rejected. Thus, there is statistical evidence that students and teachers have equivalent agreement level regarding the four statements about video lectures.

Table 9 - Results of the Mann-Whitney test regarding statements about video lectures

\begin{tabular}{|l|c|c|}
\hline \multicolumn{1}{|c|}{ Statement } & p-valor & Conclusion \\
\hline $\begin{array}{l}\text { 1. The video lecture style can interfere in the learning } \\
\text { process }\end{array}$ & 0.7577 & Accept $\mathrm{H}_{0}$ \\
\hline $\begin{array}{l}\text { 2. The video lecture in which the teacher speaks fast and with } \\
\text { great enthusiasm is more engaging }\end{array}$ & 0.9064 & Accept $\mathrm{H}_{0}$ \\
\hline $\begin{array}{l}\text { 3. The video lecture in which the teacher talks rhythmically } \\
\text { facilitates understanding }\end{array}$ & 0.9559 & ${\text { Accept } \mathrm{H}_{0}}^{\text {4. The video lecture that interpolates teacher's image with slides }}$ \\
\hline is more attractive & 0.6752 & ${\text { Accept } \mathrm{H}_{0}}$ \\
\hline
\end{tabular}

\section{Conclusion}

The survey with students and teachers of technical courses has resulted in important data about preferences in relation to video lectures. The results obtained using descriptive statistical analysis mainly showed the preferences regarding video lecture styles and duration of video lectures. The comparison between preferences of students and teachers indicated a conflict between the preferred style of students, tutorial style, and the preferred style of teachers, voice and presentation style. However, the style called image, voice and presentation is the second style in both preferences. Specifically, regarding production of video lectures by teachers, most of them expressed not knowing 
any method or technique for producing video lectures. Despite this last result, most teachers also said that are predisposed to learn new methods and techniques for producing video lectures and to learn how to use new production tools.

The results obtained by inferential statistical analysis showed that both students and teachers agree that video lecture style can interfere in the learning process, video lecture in which the teacher speaks fast and with great enthusiasm is more engaging, video lecture in which the teacher talks rhythmically facilitates understanding, and video lecture that interpolates teacher's image with slides is more attractive. The results indicated that there is statistical evidence that students and teachers have equivalent agreement level regarding these statements about video lectures.

The results suggest some directions for planning a training program for teachers on production of video lectures. For example, such program should emphasize the production of short video lectures, reinforce the styles preferred by students, include some method or technique of production, and adopt tools preferred by teachers. Specifically, regarding training in a tool for producing video lectures, some activities could provide predefined templates and systematic diagrams to produce video lectures in different styles. Moreover, the training could provide strategies to control the duration of video lecture during production and analyze the teacher's voice to indicate the need for changing the pace. Finally, a training strategy could link a method or technique with tool features to support video lecture production or at least associate them to the stages of planning (pre-production), recording (production) and editing (post-production).

One of the future works that could continue the study presented in this paper involves a deeper investigation of aspects related to video lecture production by teachers. The predisposition to learn new methods and techniques for video lecture production and to learn how to use new production tools suggests the need for further research to identify difficulties that teachers encounter in this task. Ultimately, this study benefits researchers from different areas by giving them information related to the use and production of video lectures. Thus, the results represent advances in the state of the art for video lectures mainly in the context of their use by students and teachers and its preferences.

\section{References}

BRECHT, H.D. Learning from online video lectures. Journal of Information Technology Education: Innovations in Practice, n. 1, 2012, p. 227-250.

CRONBACH, L.J. Coefficient alpha and the internal structure of tests. Journal Psychometrika, v. 16, n. 3, 1951, p. 297-334.

CRONBACH, L.J.; SHAVELSON, R.J. My current thoughts on coefficient alpha and successor procedures. Educational and psychological measurement, v. 64, n. 3, 2004, p. 391-418.

CROSS, A.; BAYYAPUNEDI, M.; CUTRELL, E.; AGARWAL, A.; THIES, W. TypeRighting: combining the benefits of handwriting and typeface in online educational videos. In: SIGCHI Conference on Human Factors in Computing Systems, 2013, France. Proceedings. p. 793-796.

DOTTA, S.C.; JORGE, E.C.; PIMENTEL, E.P.; BRAGA, J.C. Análise das Preferências dos Estudantes no uso de Videoaulas: Uma experiência na Educação a Distância. In: Congresso Brasileiro de Informática na Educação - XIX Workshop de Informática na Escola, 2., 2013, Campinas. Anais. p. 21-30.

GILARD, M.; HOLROYD, P.; NEWBURY, P.; WATTEN, P. The effects of video lecture delivery formats on student engagement. In: Science and Information Conference, 2015, London. Proceedings. p. 791-796. 
GROSSMAN, T.; FITZMAURICE, G.; ATTAR, R. A Survey of Software Learnability: Metrics, Methodologies and Guidelines. In: SIGCHI Conference on Human Factors in Computing Systems, 2009, Boston. Proceedings. p. 649-658.

GUO, P. J.; KIM, J.; RUBIN, R. How video production affects student engagement: an empirical study of MOOC videos. In: ACM Conference on Learning at Scale, 1., 2014, Atlanta. Proceedings. p. 41-50.

ILIOUDI, C.; GIANNAKOS, M.N.; CHORIANOPOULOS, K. Investigating Differences among the Commonly Used Video Lecture Styles. In: Workshop on Analytics on Video-based Learning, 2013, Leuven. Proceedings. p. 21-26.

STREINER, D.L. Being inconsistent about consistency: when coefficient alpha does and doesn't matter. Journal of Personality Assessment, n. 80, 2003, p. 217-222.

VIEIRA, I.; LOPES, A.P.; SOARES, F. The potential benefits of using videos in higher education. In: International Conference on Education and New Technologies, 6 ., 2014, Barcelona. Proceedings. p. 750-756.

WINTER, J.C.F.; DODOU, D. Five-point Likert items: $t$ test versus Mann-WhitneyWilcoxon. Practical Assessment, Research \& Evaluation, v. 15, n. 11, 2010, p. 112 . 